\title{
ECO Lets: Uma Rede Social para Doação de Materiais Recicláveis
}

\section{Clébert Clark Nunes da Silva Júnior¹, Eliamilton Barbosa das Chagasª , Gildson Borges Feitosa $^{1}$, Ronaldo Pires Borges ${ }^{1}$, Vanessa Veloso Aragão ${ }^{1}$}

${ }^{1}$ Curso de Tecnologia em Análise e Desenvolvimento de Sistemas - Instituto Federal de Educação, Ciência e Tecnologia do Piauí (IFPI) - Campus Floriano.

Rua Francisco Urquiza Machado, 462, Bairro Meladão - CEP: 64.808-475 - Floriano -

$$
\text { PI - Brazil }
$$

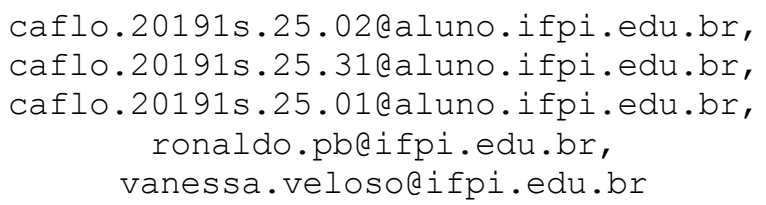

Resumo. A cultura de consumo atual tem gerado uma maior pressão sobre o meio ambiente devido ao grande acúmulo de resíduos sólidos descartados como rejeito (lixo comum), situação essa agravada pela falta de programas mais eficazes de coleta seletiva nos municipios brasileiros. O ECO Lets tem o objetivo de verificar a relevância de uma rede social voltada para reutilização e reciclagem de resíduos sólidos, podendo contribuir como ferramenta de transformação do olhar de seus usuários finais sobre o que se entende por "lixo". Após a implementação e apresentação da plataforma web, foi realizado um questionário que confirmou o interesse de possíveis usuários finais na utilização de uma rede social com o viés ambiental.

Abstract. The current consumer culture has generated greater pressure on the environment due to the large accumulation of solid waste discarded as waste (common garbage), a situation aggravated by the lack of more effective selective collection programs in Brazilian municipalities. ECO Lets aims to verify the relevance of a social network aimed at reusing and recycling solid waste, and can contribute as a tool for transforming the view of its end users on what is meant by "garbage". After the implementation and presentation of the web platform, a questionnaire was carried out that confirmed the interest of possible end users in the use of a social network with an environmental bias. 


\section{Introdução}

A Lei No 12.305 de 2010, que instituiu a Política Nacional de Resíduos Sólidos, tinha por meta extinguir todos os lixões a céu aberto e aterros sanitários irregulares até o ano de 2014. Mas, dez anos após a sua promulgação, esse objetivo ainda não foi concretizado. A solução foi adiar os prazos dessa adequação para os próximos anos, levando em consideração a densidade demográfica dos diferentes municípios brasileiros. Assim, os mais populosos devem se adequar antes.

Atualmente percebe-se um esforço maior por parte das empresas multinacionais, no que diz respeito à inovação no trato ambientalmente adequado do resíduo gerado por sua atividade econômica, uma vez que as mesmas têm interesse em acessar novos mercados, que exigem certificações rigorosas como a International Organization for Standardization - ISO 14001, para fazer negócios com outros países. Tendo em vista o cenário apresentado, questiona-se o papel que todos devem desempenhar na luta contra o desperdício e a favor do desenvolvimento sustentável - aquele que garante o sustento da geração presente sem afetar o sustento das próximas gerações.

Nesse contexto, o ECO Lets se coloca como uma solução tecnológica que proporciona aos seus usuários fazer parte de uma rede social de doação de resíduos sólidos, permitindo a diminuição da pressão no meio ambiente causado pelo grande volume de resíduos descartados irregularmente na natureza. Dessa forma, a ideia é fazer com que pessoas e empresas conectem-se umas com as outras com o intuito de oferecer uma reutilização ou reciclagem daquilo que normalmente é descartado como rejeito. A intenção é encarar o "lixo" como algo que tem valor econômico para outrem.

Como ponto de partida da proposta supracitada, tem-se que, no município de Floriano - PI, ainda não há coleta seletiva de resíduos sólidos e existem poucas iniciativas privadas que trabalham com materiais recicláveis. A solução proposta pode ser utilizada como uma alternativa para diminuir o impacto do lixo gerado, pois permite a possibilidade de alguém doar um material que julga não ter mais valor, para outra pessoa que consiga capitalizar aquilo que seria descartado sem o tratamento adequado.

Diante do exposto, o ECO Lets pode auxiliar na diminuição da pressão exercida sobre o meio ambiente, uma vez que os municípios ainda não se adaptaram à realidades mais sustentáveis no trato com o lixo. O município de Floriano, por exemplo, trabalha com aterro controlado, que cobre com camadas de areia o lixo, mas causa impacto ambiental negativo, já que polui o lençol freático, pois não impermeabiliza o solo.

Assim, a Política Nacional de Resíduos Sólidos determina metas para redução, reutilização e reciclagem com o intuito de diminuir a quantidade de resíduos e rejeitos encaminhados para a disposição final ambientalmente adequada. Visando esse resultado, a rede social implementada tem por missão auxiliar nestas metas, pois conecta pessoas/empresas interessadas em se desfazer de algum resíduo a pessoas/empresas interessadas em reutilizar ou reciclar este material. Com isso, espera-se a ampliação desta rede de preservação que utiliza a tecnologia a serviço da comunidade a partir da busca por um ambiente mais saudável para toda a coletividade.

Portanto, o ECO Lets contribui significativamente no âmbito social e ambiental, pois, ao criar uma rede colaborativa entre pessoas e empresas, possibilita a 
ressignificação do que antes era considerado apenas como"lixo", ao oferecer uma destinação adequada àquilo que, sem os cuidados necessários, tornaria-se um agente potencialmente poluidor no aterro da cidade. O objetivo do corrente trabalho é verificar a relevância de uma rede social com o viés descrito anteriormente, no município de Floriano.

Por fim, São Paulo (1994 apud BERTÉ e MAZZAROTTO, 2013) diz que "Sociedade e natureza, de fato, interagem afetando-se mútua e equitativamente, porém, ambas vitalmente importantes, crescem ou desaparecem juntas.".

\section{Referencial teórico}

\subsection{A relação homem $x$ natureza}

Desde os primórdios da humanidade, que o homem tem impactado o ambiente ao seu redor. A princípio, a interação com a natureza se dava de maneira sustentável, pois vivia-se como caçador-coletor, extraindo apenas o necessário para manutenção da vida. Com a evolução da humanidade, o homem agrupou-se em cidades, o que aumentou consideravelmente a pressão sobre o meio ambiente. (HARARI, 2011).

De acordo com Berté e Mazzarotto (2013) o homem viveu em relativa harmonia com a natureza até o surgimento da Revolução Industrial, no século XVIII, época onde o crescimento populacional acelerou a ponto de haver uma maior demanda por mercadorias. Desde então, a visão antropocêntrica - o homem no centro do universo imperou. Com isso, a natureza passou a ser encarada como um recurso infindável que estaria sempre a disposição, satisfazendo todas as necessidades do homem. (BERTÉ e MAZZAROTTO, 2013)

A preocupação com os recursos naturais foi discutida de maneira mais efetiva somente no ano de 1968 quando um grupo de cientistas, pedagogos, industriais, economistas, funcionários públicos e humanistas, se reuniram no que ficou conhecido como o "Clube de Roma", para debater sobre o crescimento econômico e o meio ambiente. O resultado deste encontro gerou o documento conhecido como "Os Limites do Crescimento", que como o próprio nome sugere, trata da iminente escassez dos recursos naturais. (BERTÉ e MAZZAROTTO, 2013)

Com isso, o debate sobre a relação do homem com a natureza passou a ser mais frequente em eventos que reuniram a maioria dos países do mundo. Destes encontros, pode-se destacar a Conferência das Nações Unidas sobre o Meio Ambiente (Conferência de Estocolmo) em 1972 e a Conferência das Nações Unidas sobre o Meio Ambiente e o Desenvolvimento (ECO-92 ou Rio-92), que deixou de legado o documento Agenda 21, que trata dos princípios e intenções para os cuidados com o planeta para o século XXI.

Dentre as preocupações ambientais discutidas nos mais diversos eventos mundo afora, este trabalho centra esforços na questão da geração de resíduos sólidos e a pressão que estes fazem sobre o meio ambiente, tendo em vista que as políticas públicas atuais não dão conta de resolver sozinhas o dano causado à natureza. O resíduo descartado indevidamente estará inerte na natureza por diversas gerações humanas, 
portanto, entende-se que o uso da tecnologia pode contribuir positivamente nesta questão.

\subsection{O papel das redes sociais na consciência ambiental}

Com o advento da internet e o surgimento de redes sociais como Facebook, Instagram, Twitter e outras, qualquer pessoa com um celular conectado à rede passou a ter voz nos mais diversos campos de discussão. Partiu-se de décadas de comunicação centralizada na grande mídia para um cenário descentralizado, que permite a amplificação dos diferentes discursos, atingindo escalas inimagináveis antes dos anos 2000. (SEVERO et al., 2017)

Severo et al. (2017, p. 3) define as redes sociais como "As conexões sociais e interconexões entre os usuários, com o potencial de atingir e engajar outros indivíduos, ou seja, são meios de comunicação que proporcionam as construções de relacionamentos". Para o autor é através das redes sociais que as pessoas têm se atentado e engajado cada vez mais nas questões ambientais, uma vez que estas se deparam com informações de que a proteção ambiental não deve ser responsabilidade apenas das empresas e do Estado, mas sim de todos.

A rede social ECO Lets busca utilizar a escalabilidade que as redes sociais proporcionam, tendo em vista que qualquer pessoa/ empresa pode aderir a ela, independente de sua localização geográfica de origem. A ideia é conectar pessoas e empresas através de uma rede social voltada a questão ambiental, observando-se que " $\mathrm{O}$ acesso às redes sociais vêm aumentando exponencialmente nos últimos anos, pois permite a interação, troca de informações, união de ideias em torno de valores e interesses compartilhados entre seus membros", Severo et al. (2017, p. 3). Assim, acredita-se que uma rede social pode ampliar o engajamento das pessoas na responsabilidade coletiva de preservar o ambiente saudável para todos.

\subsection{Resíduos sólidos: uma responsabilidade coletiva}

Segundo dados do Instituto Brasileiro de Geografia e Estatística - IBGE (2010, apud SALVI e YAMAWAKI, 2013), em levantamento sobre a destinação final dos resíduos sólidos, realizado entre os anos 1989 e 2008, partiu-se de uma realidade onde 88,2\% dos resíduos sólidos eram jogados em vazadouros a céu aberto, "lixões", para uma situação de 50,8\% no mesmo quesito, o que mostra uma redução $37,4 \%$ do número de lixões em 20 anos. Por outro lado, a mesma pesquisa mostra que apenas $27,7 \%$ dos resíduos são destinados a aterros sanitários ambientalmente adequados, que são aqueles certificados e que possuem impermeabilização do solo, impedindo dano causado pelo "chorume" ao lençol freático. 
Com isso, surge a Lei 12.305 de 2010, que determinava que a disposição final ambientalmente adequada de resíduos sólidos deveria ocorrer até o ano de 2014. Novos prazos foram dados, tendo em vista que a maioria dos municípios não conseguiu se adequar a tempo. A cidade de Floriano - PI, por exemplo, deverá se adaptar até agosto de 2023, por conta de ser um município com população entre 50 mil a 100 mil habitantes. No município há um aterro controlado, que cobre o lixo com camadas de areia, o que ainda não é o ideal, pois não há impermeabilização do solo.

Para Salvi e Yamawaki (2013, p. 379) o impacto dos resíduos deve ser levado a sério pois "é uma forma de poluição que exerce intenso impacto negativo sobre o solo, o ar e os recursos hídricos". Para os autores, não há como encarar essa questão apenas com o recolhimento e afastamento do lixo dos centros urbanos, pois esta prática gera a sensação de que o lixo urbano não é um problema, uma vez que a população em geral não estaria convivendo com o problema.

Desta forma, o ECO Lets pode ser mais uma ferramenta no processo de logística reversa, que segundo Berté e Filho (2013) faz com que o resíduo seja reinserido na cadeia produtiva, voltando do ponto de consumo para a produção. Para tanto, utilizou-se de uma rede social, pois a capacidade de mobilização de pessoas com ideais comuns é potencializada. Com isso, podemos alinhar a luta em prol da natureza à Constituição Federal do Brasil de 1988, que no seu artigo 225 prevê que todos têm o direito ao meio ambiente equilibrado e que a coletividade tem o dever de defendê-lo e preservá-lo para as presentes e futuras gerações.

Indo ao encontro da ideia do ECO Lets, observou-se o site Cata Amazon, iniciativa da Universidade Federal do Pará - UFPA, que se utiliza do ambiente da internet com o objetivo de proporcionar um espaço organizado para que cooperativas e associações de catadores do estado do Pará possam divulgar o seu trabalho e produzir conteúdo. Esta ferramenta se assemelha ao ECO Lets no sentido de que ambas utilizam a tecnologia para conectar iniciativas ambientais relacionadas aos resíduos sólidos, porém, cabe ressaltar, que há uma diferença: o formato de rede social proposto neste trabalho, que permite uma interação maior entre os usuários, tendo em vista que a iniciativa do Cata Amazon apenas fornece o contato do Facebook de algumas associações parceiras. Outra limitação enfrentada pela plataforma desenvolvida pela UFPA é a regionalização da iniciativa, pois limita-se ao estado do Pará.

Por fim, ressalta-se a necessidade da ampliação de alternativas para lidar com a questão do lixo, tendo em vista que o relatório da Associação Brasileira de Empresas de Limpeza Pública e Resíduos Especiais - Abrelpe (2019, apud CATAMAZON, 2019) alerta que a sociedade está gerando lixo acima da capacidade de lidar com os resíduos. Ainda sobre esta pesquisa, importa salientar que o Brasil ocupa a primeira posição na América Latina, no quesito maior gerador de lixo, com 40,5\% sendo despejado de maneira ambientalmente inadequada. 


\section{Metodologia}

Inicialmente, foi realizado um levantamento bibliográfico sobre resíduos sólidos e os seus impactos ambientais. Somado a isso, pesquisou-se como as redes sociais podem servir como ferramenta para engajar pessoas em prol de ideias em comum. Também foi feita uma pesquisa de soluções tecnológicas semelhantes à proposta neste trabalho, com o intuito de aprimorar a modelagem da aplicação final do ECO Lets.

Num segundo momento, foram realizadas modelagens com a linguagem UMLUnified Modeling Language - que permite a criação de diagramas de classe e de casos e usos, dentre outros. Esta linguagem é importante na comunidade de desenvolvedores, pois permite uma visão prévia de como o sistema estará estruturado, além de traçar as suas principais funcionalidades.

A terceira fase do projeto foi dedicada à implementação da aplicação em si. Para tanto, foram utilizadas as tecnologias HTML, CSS e Javascript para tratar o aspecto visual e de comportamento do frontend da página web. A escolha pelo Javascript se deu por se tratar de uma tecnologia largamente utilizada, com bastante material produzido, de fácil acesso para consulta. Já com relação às tecnologias CSS e HTML, ambas foram escolhidas porque são o padrão de desenvolvimento de páginas web; a primeira permite mudanças no estilo da página com um melhor reaproveitamento de código, facilitando a manutenção da mesma; já a segunda é a opção mais aceita entre os diferentes navegadores web.

Complementando o processo de implementação optou-se pelo Node JS para manipular o backend, pois este permite a utilização do Javascript no desenvolvimento do lado do servidor. Somado a isso, foi utilizado o PostgresSQL para implementação e manipulação do banco de dados por ser uma opção open source, com uma comunidade bastante atuante.

Por fim, no que diz respeito ao tipo de pesquisa adotado, optou-se pela utilização da pesquisa exploratória, uma vez que a temática trabalhada ainda dispõe de poucas iniciativas atuantes no Brasil. Com relação ao procedimento técnico, foi realizado um estudo de campo no município de Floriano - PI. Para tanto, foi aplicado um questionário, com perguntas de respostas fechadas do tipo múltipla escolha, dicotômica e de resposta única, além de perguntas de resposta aberta, com viés subjetivo. Os dados foram analisados de maneira qualitativa e quantitativa, uma vez que não se trabalhou apenas com números estatísticos.

\section{Análise e resultados}

A realização deste projeto tinha o intuito de verificar a relevância de uma rede social voltada para a doação de materiais recicláveis. Para tanto, foi desenvolvido uma página web que permite ao usuário final postar anúncios de algo que possui em casa e que, sem o apoio desta rede social, seria descartado como lixo comum. Para fazer postagens ou interagir com outras pessoas, é necessário que se faça um cadastro com os dados pessoais. Também é possível interações entre dois usuários —estas podem ser feitas por telefone ou ainda via Whatsapp, desde que ambos autorizem uma solicitação, que é enviada automaticamente pelo sistema (ver figura 1). 


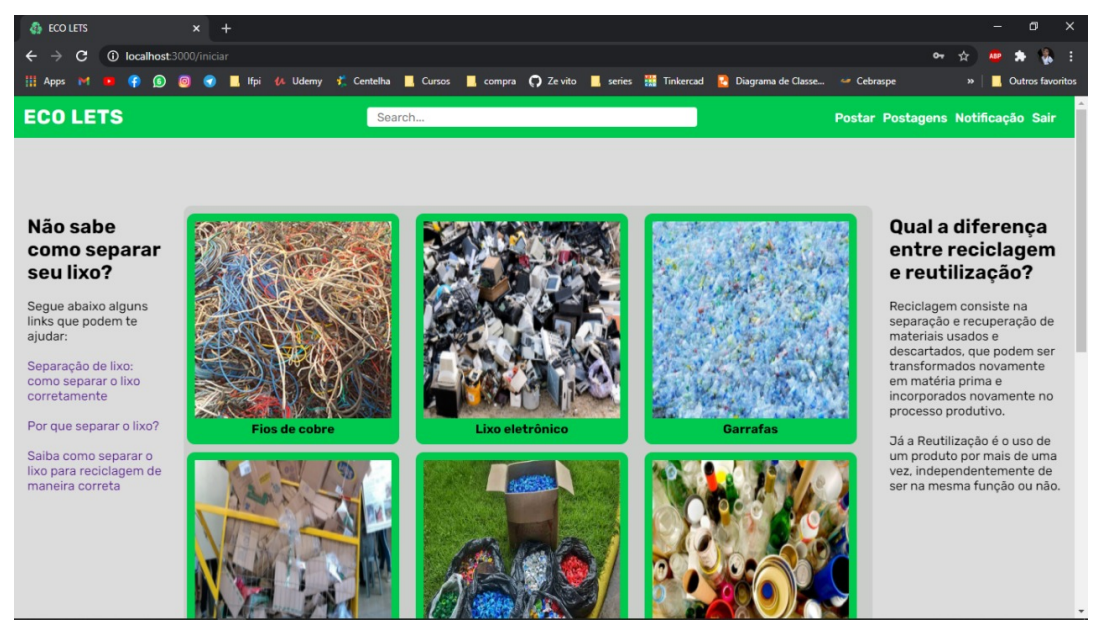

Figura 1 - Página inicial do ECO Lets.

Desta forma, após o término da implementação do sistema, foi exibido um vídeo demonstrando as funcionalidades da rede social ECO Lets. Por fim, aplicou-se um questionário que se dividiu em três momentos: de início foram feitas perguntas como idade, gênero e nível de escolaridade para traçar um perfil dos respondentes; num segundo momento tinha-se por objetivo descobrir o nível de conhecimento dos entrevistados sobre os conceitos de reutilização e reciclagem, além da sua cultura em relação à separação do lixo; a terceira e última parte foi dedicada a questões sobre a ferramenta em si. Ao todo, foram coletadas informações de 109 respondentes.

Tendo em vista o exposto acima e de posse dos dados da pesquisa foi possível fazer conclusões interessantes a respeito da rede social ECO Lets e sobre algumas questões referentes aos resíduos sólidos. Por exemplo, percebeu-se que houve baixa adesão de entrevistados na faixa etária acima de 40 anos, apenas 13,8\% participou. A maior porcentagem dos respondentes tinha de 20 a 29 anos, 33,9\%, sendo majoritariamente do gênero masculino, $61,5 \%$.

Também, pôde ser inferido que o nível de escolaridade não é fator determinante no que diz respeito ao conhecimento dos conceitos de reutilização e reciclagem, pois apesar de $71,7 \%$ dos respondentes serem de nível superior e pós-graduados, uma porcentagem relevante, $33 \%$, ainda não tinha familiaridade com estes conceitos. Dentre os entrevistados, apenas $27,6 \%$ eram de nível médio e menos de $1 \%$ de nível fundamental.

$\mathrm{Na}$ sequência do questionário foi perguntado se os entrevistados acreditavam que o lixo coletado nas residências causava impacto negativo ao meio ambiente. O que se percebeu foi que as pessoas têm essa consciência, pois $89 \%$ responderam afirmativamente. Índice similar a este foi encontrado quando perguntado se as pessoas tinham o hábito de separar o lixo nas suas casas. Neste quesito, 83,5\% responderam negativamente.

Ainda sobre a separação do lixo nas residências, $83 \%$ justificaram que não fazem este trabalho por conta da falta de coleta seletiva no município (ver figura 2). Este dado revela que uma rede social como o ECO Lets poderia auxiliar nesse sentido, uma vez 
que os resíduos estariam sendo direcionados para reutilização e/ ou reciclagem, diminuindo o volume destinado ao aterro da cidade.

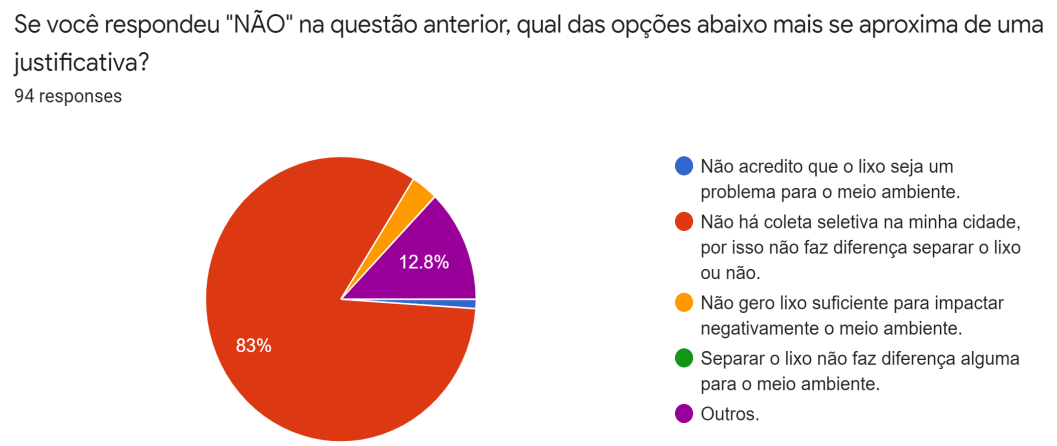

Imagem 2 - Justificativa das pessoas que não separam o lixo em casa.

Por fim, foram feitas perguntas a respeito da plataforma propriamente dita. Quando perguntado se baseado no vídeo exposto, numa escala zero a dez, qual a possibilidade de uso da ferramenta, 42,2\% indicou graduação máxima (ver figura 3), que indica "usaria com certeza". Estes índices denotam de forma clara que a ferramenta teria público, pois as pessoas se mostraram interessadas pela plataforma. Esta conclusão se confirma quando perguntado se os usuários acreditavam se o ECO Lets poderia incentivar as pessoas a separarem o seu lixo, neste quesito 97,2\% dos entrevistados acredita que sim. Com isso, chegou-se à conclusão de que a rede social desenvolvida neste trabalho é viável.

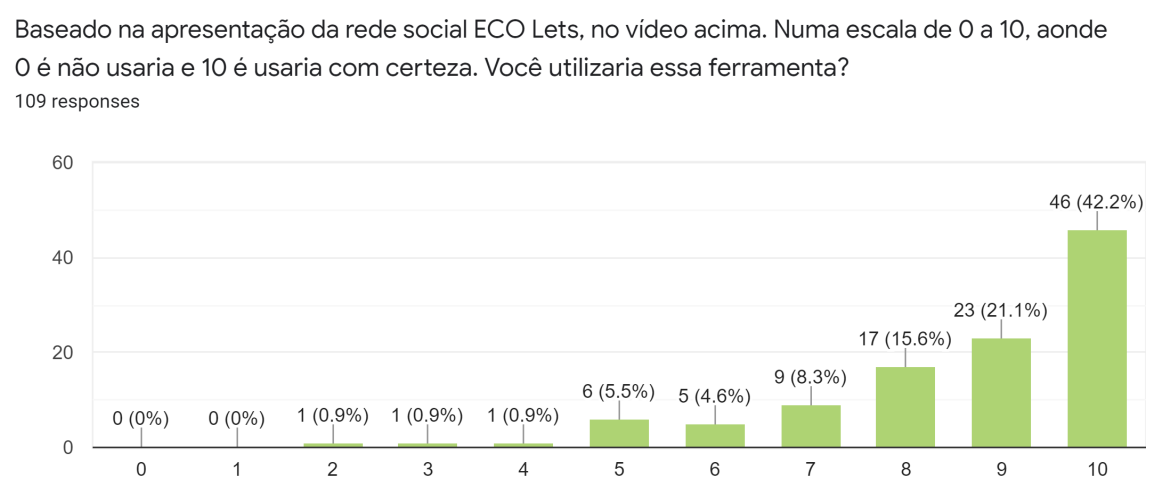

Figura 3 - Usuários avaliam se usariam a rede social ECO Lets.

Dados mais detalhados da pesquisa podem ser acessados no link disponibilizado abaixo:

https://docs.google.com/forms/d/1EPZZs5fortmmUNvHsapSAPJg2HcHu9pgHe U5dEnhJqI/edit\#responses 


\section{Considerações finais}

Considerando todo o exposto anteriormente neste artigo acredita-se que o projeto teve êxito no que se propôs inicialmente: a ferramenta desenvolvida está funcional e as pessoas se mostraram interessadas na utilização do ECO Lets. Esta primeira versão permite ao usuário criar, editar e remover postagens; fazer cadastro e login; além de possibilitar a interação, mesmo que de maneira simplificada.

Em contrapartida, acredita-se que há alguns aspectos a serem melhorados. Isto foi algo apontado por alguns entrevistados, que sugeriram uma interface mais atrativa e intuitiva. Também foi sugerido que a plataforma tivesse um viés mais ligado a gamificação, com uma espécie de pontuação para os usuários que mais separassem o seu lixo. Estas ideias podem ser um ponto de partida para evoluções futuras da plataforma.

Ainda neste sentido, pode-se adicionar outras estratégias para incentivar a separação do lixo, algo como um botão para o usuário selecionar se quer doar ou comercializar o seu material, pois o retorno monetário pode estimular uma maior adesão à iniciativa do ECO Lets. Outro aspecto que pode contribuir nesse sentido são parcerias com os municípios e empresas privadas, que poderiam dar isenção de impostos e vantagens, respectivamente, para os usuários que mais se destacarem na plataforma.

Por fim, destacamos que os objetivos da pesquisa foram alcançados, pois conseguiu-se confirmar a viabilidade de uma rede social voltada para a doação de materiais recicláveis. Os entrevistados se sentiram atraídos pela plataforma e acreditam que ela pode favorecer o meio ambiente, uma vez que deve estimular a separação e doação daquilo que seria descartado como lixo comum.

\section{Referências}

BERTÉ, Rodrigo; MACIEL, André; SILVEIRA, Augusto. Gestão de resíduos sólidos: cenários e mudanças de paradigma. 1 ed. Curitiba: Intersaberes, 2018.

BERTÉ, Rodrigo; MAZZAROTTO, Angelo de Sá. Gestão ambiental no mercado empresarial. $1^{\circ}$ edição. Curitiba: Editora Intersaberes, 2013.

BERTÉ, Rodrigo; FILHO, Edelvino Razzolini. O reverso da logística e as questões ambientais no Brasil. $1^{\circ}$ edição. Curitiba: Editora Intersaberes, 2013.

BRASIL. Constituição (1988). Constituição da República Federativa do Brasil.

Brasília, DF: Senado Federal: Centro Gráfico, 1988. Disponível em:

http://www.planalto.gov.br/ccivil 03/constituicao/constituicao.htm Acesso em: 16 fev. 2021.

BRASIL. Lei $\mathbf{n}^{\mathbf{0}} \mathbf{1 2 . 3 0 5}$, de 2 de agosto de 2010. Institui a Política Nacional de Resíduos Sólidos; altera a Lei no 9.605, de 12 de fevereiro de 1998; e dá outras providências. Disponível em:

http://www.planalto.gov.br/ccivil 03/ ato2007-2010/2010/lei/112305.htm Acesso em: 3 fev. 2021.

CATAMAZON, Produção de lixo no Brasil cresce mais que capacidade para lidar com resíduos. catamazon.net, 2019. Disponível em:

https://www.cataamazon.net/post/produ\%C3\%A7\%C3\%A3o-de-lixo-no-brasil-cresc 
e-mais-que-capacidade-para-lidar-com-res\%C3\%ADduos Acesso em: 18 de fev. 2021

HARARI, Yuval Noah. Sapiens: uma breve história da humanidade. Porto Alegre: Editora L\&PM, 2011.

SALVI, Luciani Teresa; YAMAWAKI, Yumi. Introdução à gestão do meio urbano. $1^{\circ}$ edição. Curitiba: Editora Intersaberes, 2013.

SEVERO, Eliana A. et al. A influência das redes sociais sobre a consciência

ambiental e a responsabilidade social das gerações. In: XIX ENGEMA, 2017, São Paulo. Disponível em:

https://www.scielo.br/pdf/bbr/v16n5/pt 1808-2386-bbr-16-05-500.pdf Acesso em: 2 fev. 2021. 